УДК 633.111.1:581.1:631.52

ИССЛЕДОВАНИЕ ПЕРИОДА ФОТОСИНТЕТИЧЕСКОЙ АКТИВНОСТИ ФЛАГОВОГО ЛИСТА МЯГКОЙ ПШЕНИЦЫ В ЗАВИСИМОСТИ ОТ ВОДООБЕСПЕЧЕННОСТИ

\author{
1 Джахангиров А.А., ${ }^{1,2}$ Мамедова С.М., ${ }^{1}$ Аллахвердиев Т.И., \\ ${ }^{3}$ Гусейнова И.М., ${ }^{1}$ Гамидов Г.Н. \\ ${ }^{1}$ Научно-исследовательский институт земледелия Министерства сельского хозяйства \\ Азербайджанской Республики, Баку, е-таil: a.cahangir@hotmail.com; \\ ${ }^{2}$ Институт генетических ресурсов НАНА, Баку; \\ ${ }^{3}$ Институт молекулярной биологии и биотехнологий НАНА, Баку
}

\begin{abstract}
В статье представлены результаты исследования периода фотосинтетической активности флагового листа (ФАФЛ) у сортов мягкой пшеницы местного и зарубежного происхождения в зависимости от водообеспеченности. Из 21 генотипа озимой пшеницы, изученного в условиях засухи и орошения, период фотосинтетической активности флагового листа в условиях засухи у сортов Муров 2, Зирва 85 и Гырмызы гюл 1 составлял $587,557,592^{\circ} \mathrm{C}$ и $662,657,630^{\circ} \mathrm{C}$ в условиях орошения, что выше, чем у других генотипов. Самый низкий результат наблюдался у сортов Безостая $1\left(460^{\circ} \mathrm{C}\right)$, Восторг $\left(468^{\circ} \mathrm{C}\right)$, Гызыл бугда $\left(469^{\circ} \mathrm{C}\right)$, Гобустан $\left(466^{\circ} \mathrm{C}\right)$, а также у линий 12 thIWWYT №9 $\left(443^{\circ} \mathrm{C}\right)$ в условиях засухи. Снижение периода ФАФЛ в условиях засухи по сравнению с условиями орошения для всех генотипов составило в среднем 15,8\%. Наибольшее снижение этого показателя наблюдалось у сортов Гобустан $(20,1 \%)$ и Фатима $(17,5 \%)$, а также у линий $12^{\text {th }}$ IWWYT №6, 12 th $I$ tWYT№17, $12^{\text {th }} I W W Y T № 8$ и $7^{\text {th }}$ WONSA№465. В то же время наименьшее снижение наблюдалось у генотипов Муров 2 (11,3\%), Шеки 1 (12,8\%), Безостая 1 (12,9\%) и Сонмез (13,9\%). Корреляция была исследована, обратная корреляция между временем колошения и периодом ФАФЛ = $-0,547$ * была обнаружена. Низкий период ФАФЛ у раннеколосящихся генотипов Гобустан, Гызыл бугда, 12 ${ }^{\text {th }}$ IWWYT№6, $12^{\text {th }}$ IWWYT№17 и 4FEFWSN №50 объясняется их слабой физиологической устойчивостью. Установлено, что сумма активных температур (САТ) генотипов озимой пшеницы в условиях орошения выше, чем в условиях засухи, что также зависит от генотипических характеристик растения. Помимо связи САТ с временем колошения, здесь также играет роль физиологическая устойчивость генотипа. Таким образом, несмотря на раннее колошение некоторых генотипов, их слабая физиологическая устойчивость привела к низкой САТ. У некоторых позднеколосящихся генотипов САТ была высокой.
\end{abstract}

Ключевые слова: озимая пшеница, водообеспечение, флаговый лист, фотосинтетическая активность

\title{
STUDY OF THE PERIOD OF PHOTOSYNTHETIC ACTIVITY OF THE FLAG LEAF OF BREAD WHEAT DEPENDING ON WATER SUPPLY
}

${ }^{1}$ Jahangirov A.A., ${ }^{1,2}$ Mamedova S.M., ${ }^{1}$ Allahverdiev T.I., ${ }^{3}$ Huseynova I.M., ${ }^{1}$ Hamidov H.N. ${ }^{1}$ Research Institute of Crop Husbandry of the Ministry of Agriculture of the Republic of Azerbaijan, Baku, e-mail: a.cahangir@hotmail.com; ${ }^{2}$ Institute of Genetic Resources of ANAS, Baku;

${ }^{3}$ Institute of Molecular Biology and Biotechnology of ANAS, Baku

\begin{abstract}
The article presents results of a study of flag leaf photosynthetic activity period (PAFL) in local and different origin bread wheat varieties, depending on the water supply. Of the 21 genotypes of winter wheat studied under drought and irrigation conditions, period of photosynthetic activity of flag leaf under drought conditions of varieties Murov 2, Zirva 85 and Gyrmyzy gul 1 was $587,557,592^{\circ} \mathrm{C}$ and $662,657,630^{\circ} \mathrm{C}$ under irrigation, which is higher than other genotypes. The lowest result was observed in varieties Bezostaya $1\left(460^{\circ} \mathrm{C}\right)$, Vostorg $\left(468^{\circ} \mathrm{C}\right)$, Gyzyl bugda $\left(469^{\circ} \mathrm{C}\right)$, Gobustan $\left(466^{\circ} \mathrm{C}\right)$, as well as in lines $12^{\text {th }} \mathrm{IWWYT}$ №9 $\left(443^{\circ} \mathrm{C}\right)$ under drought conditions. The decrease in the FLFA period under drought conditions compared to irrigation for all genotypes averaged $15.8 \%$. The greatest decrease in this indicator was observed in varieties Gobustan $(20.1 \%)$ and Fatima $(17.5 \%)$, as well as in lines $12^{\text {th }} I W W Y T$ №6, $12^{\text {th }} I W W Y T$ №17, $12^{\text {th }} I$ WWYT №8 and $7^{\text {th }} W O N S A$ №465. №6, $12^{\text {th }} I W W Y T № 17,12^{\text {th }} I W$ WYT№8 и $7^{\text {th }}$ WONSA№465. At the same time, the smallest decrease was observed in genotypes Murov $2(11.3 \%)$, Sheki 1 (12.8\%), Bezostaya 1 (12.9\%) and Sonmez (13.9\%). The correlation was investigated, an inverse correlation between the heading time and the period of FLFA $=-0.547 *$ was found. The low period of FAFL in early heading genotypes Gobustan, Gyzyl bugda, 12 ${ }^{\text {th }}$ IWWYT №6, 12 $12^{\text {th }}$ IWWYT №17 and 4FEFWSN №50 is explained by their weak physiological resistance. It was found that the sum of active temperatures (SAT) of winter wheat genotypes under irrigation conditions is higher than under drought conditions, which also depends on the genotypic characteristics of plant. In addition to relationship of SAT with the time of heading, the physiological resistance of genotype also plays a role here. Thus, despite the early heading of some genotypes, their weak physiological resistance led to a low SAT. SAT was high in some late heading genotypes.
\end{abstract}

Keywords: winter wheat, water supply, flag leaf, photosynthetic activity

Пшеничный хлеб является основным источником питания в Азербайджане. Удовлетворение потребности населения без уве- личения площади пахотных земель, за счет повышения продуктивности с единой площади, является главным эффективным спо- 
собом в сельском хозяйстве. Частые засухи, происходящие в последнее время, являются одним из снижающих урожайность пшеницы климатических факторов. Существует много аспектов засухоустойчивости растений. С точки зрения засухоустойчивости физиологические, морфологические и биохимические системы растений образуют сложные структуры. В условиях засухи взаимодействие между этими системами и их связь с урожайностью еще больше усложняют ситуацию. Несмотря на проведение многочисленных исследований по некоторым морфологическим и физиологическим параметрам, которые могут быть использованы в качестве критериев засухоустойчивости, все же существует необходимость в продолжении этих исследований и применении их результатов в селекции.

Использование оптимальных морфобиологических, физиологических и агрономических признаков при выборе сортов пшеницы, которые можно выращивать в условиях водного стресса, является одним из ключевых условий успеха. Для достижения лучших результатов, полученных в этой области, считается необходимым использование физиологических параметров на всех этапах отбора [1-3].

При селекции пшеницы важно определение физиологических параметров, таких как устойчивость к засухе и другим стрессовым факторам, и оценка на этой основе исходного материала [4; 5].

Так, изучение периода фотосинтетической активности флагового листа (ФАФЛ) у отличающихся по морфофизиологическим характеристикам генотипов озимой мягкой пшеницы в условиях водного стресса считается актуальным.

Представленная работа посвящена изучению периода фотосинтетической активности флагового листа генотипов озимой мягкой пшеницы в различных условиях водообеспечения.

\section{Материалы и методы исследования}

Исследования проводились на Гобустанской зональной опытной станции (ЗОС) НИИ Земледелия в 2013 и 2014 годах. В 2012-2013 гг. за вегетационный период (октябрь-май) количество осадков составило 385,3 мм, что было равно норме, а в 2013-2014 гг. - 222,8 мм, что значительно ниже нормы (данные Гобустанской гидрометеостанции). В качестве объекта исследования были взяты 12 сортов и 9 линий мягкой пшеницы, различающихся по мор- фофизиологическим характеристикам. Площадь каждой опытной делянки составила 1,0 м², и произвольно размещенные блоки высаживались в трех повторностях, норма

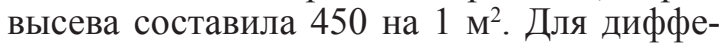
ренцирования водообеспечения в начале мая в одном блоке было создано условие искусственной засухи, путем накрывания одного блока прозрачным полиэтиленовым покрытием, а на втором блоке производился полив. Значения SPAD (общее количество хлорофилла) флагового листа, измеренные в разные даты с помощью SPAD-метра, приняты как зависимые переменные (y), дневная степень роста (ДСР - GDD), рассчитанные с даты колошения до даты измерения SPAD, как свободные переменные (x), и построен между ними график квадратичной регрессии. На основе графика была найдена теоретическая точка, в которой содержание хлорофилла падает до нуля, и сумма активных температур (САТ), соответствующая этой точке, была использована для количественной оценки активности флагового листа [6].

\section{Результаты исследования и их обсуждение}

Динамика хлорофилла во флаговом лиcme. Общее количество хлорофилла во флаговом листе генотипов в условиях засухи и орошения в 2012-2013 и 2013-2014 гг. в вегетационный период измерялось несколько раз в разные даты с помощью SPAD-метра и оценивалось в единицах SPAD. За исключением сорта Аран в варианте засухи, максимальное содержание хлорофилла во флаговом листе у изученных генотипов наблюдалось 20 и 26 мая 2013 г. В последующих измерениях в этом варианте в зависимости от генотипа содержание хлорофилла снизилось и приблизилось к нулю 16, 18 и 20 июня. В том же году максимальное содержание хлорофилла в условиях орошения наблюдалось 8 и 11 июня. В последующих измерениях 20 июня значение упало почти до нуля для генотипов Гобустан, Тале 38, Ferrigineum 2/19, $12^{\text {th }}$ IWWYT № 6, $12^{\text {th }} I W W Y T$ № 8, $12^{\text {th }}$ IWWYT № 9, $12^{\text {th }} I W W Y T$ № 17 , 4 thFEFWSN №50, 24 июня - для генотипов Безостая 1, Гызыл Бугда, Фатима, $7^{\text {th }} \mathrm{WON}-$ SA № 465, $11^{\text {th }} I W W Y T$ №20， $7^{\text {th }}$ WON-SA № 477 и 26 июня - для генотипов Шеки 1, Аран и Восторг. В 2013 году содержание хлорофилла оставалось максимальным в течение более длительного периода времени, а затем за более поздний период 
приблизилось к нулю. Максимальное содержание хлорофилла во флаговом листе генотипов в обоих вариантах эксперимента было зафиксировано 19 и 27 мая 2014 г. Позже, 6 и 9 июня, величина этого параметра в условиях засухи приблизилась к нулю, что в условиях орошения наблюдалось 12 и 16 июня.

В 2014 году максимальный уровень содержания хлорофилла сохранялся непродолжительное время и вскоре достиг нуля.

Фотосинтетическая активность флагового листа. Существуют литературные данные о зависимости продуктивности от скорости фотосинтеза флагового листа и продолжительности его активности [7; 8]. Также по фотосинтетической активности у пшеницы отмечалось наличие генетических различий $[9 ; 10]$.

Фотосинтетичская активность для каждого генотипа была рассчитана на основе того дня, когда значения SPAD-CAT теоретически упали до нуля. Этот параметр позволяет количественно оценить активность растения в период формирования зерна. Такая оценка генотипов также помогает сравнить характеристики флаговых листьев во время стресса, вызванного засухой.

Значения ФАФЛ исследуемых сортов и линий, полученные в условиях засухи и орошения, приведены на рис. 1. лись у генотипов Безостая $1\left(528^{\circ} \mathrm{C}\right)$, Восторг $\left(534^{\circ} \mathrm{C}\right)$, Тале $38\left(549^{\circ} \mathrm{C}\right), 12^{\text {th }} \mathrm{IWWYT}$ №9 $\left(522^{\circ} \mathrm{C}\right)$ и $12^{\text {th }} I W W Y T$ №17 $\left(535^{\circ} \mathrm{C}\right)$. А в условиях засухи самые высокие значения этого параметра были у сортов Муров 2, Зирва 85, Гырмызы гюл 1 и составили 587 , 557 и $532^{\circ} \mathrm{C}$ соответственно. Самые низкие значения наблюдались у генотипов Безостая $1\left(460^{\circ} \mathrm{C}\right)$, Восторг $\left(468^{\circ} \mathrm{C}\right)$, Гызыл бугда $\left(469^{\circ} \mathrm{C}\right)$, Гобустан $\left(466^{\circ} \mathrm{C}\right), 12^{\text {th }} \mathrm{IWWYT}$ №17 $\left(420^{\circ} \mathrm{C}\right), \quad 12^{\text {th }} I W W Y T$ № $6 \quad\left(437^{\circ} \mathrm{C}\right)$ и $12^{\text {th }}$ IWWYT №9 $\left(443^{\circ} \mathrm{C}\right)$. Ожидалось, что значения САТ будут выше из-за раннего колошения сортов Сонмез 01, Зирва 85, Муров 2 и позднего высыхания флаговых листьев, но это значение также было высоким у позднеколосящегося Гырмызы гюл 1. Это можно объяснить тем, что, несмотря на позднее колошение, он обладает физиологической устойчивостью и сохраняет листья зелеными в течение более длительного периода времени. Следует отметить, что повышение среднесуточной температуры к концу периода налива зерна может привести к увеличению значений ФАФЛ у сортов с поздним колошением, таких как Гырмызы гюл 1.

Средние значения САТ исследуемых генотипов за два года в условиях засухи и орошения представлены на рис. 2 .

В 2013 и 2014 годах среднее значение САТ для всех генотипов в условиях засу-

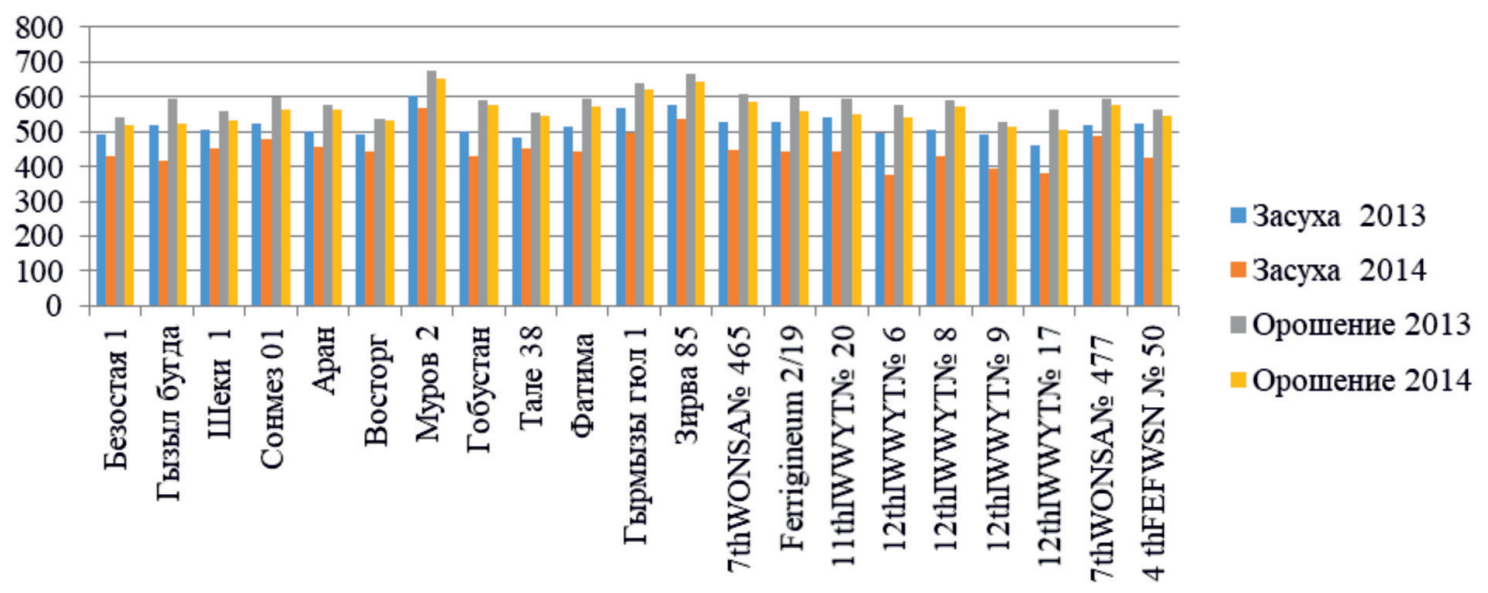

Рис. 1. Фотосинтетическая активность флагового листа (ФАФЛ), (САТ), ${ }^{\circ} \mathrm{C}$

По среднему показателю за два года самые высокие значения САТ наблюдались у сортов Муров $2\left(662^{\circ} \mathrm{C}\right)$, Зирва $85\left(657^{\circ} \mathrm{C}\right)$ и Гырмызы гюл $1\left(630^{\circ} \mathrm{C}\right)$, и у линий $7^{\text {th }}$ WONSA $№ 465\left(597^{\circ} \mathrm{C}\right)$, $7^{\text {th }}$ WONSA №477 $\left(586^{\circ} \mathrm{C}\right)$. В этом варианте наименьшие значения по этому параметру наблюда- хи и орошения составило 518, 588 и 449, $561^{\circ} \mathrm{C}$, и в 2013 году среднее значение, соответственно, выше. В этом случае разница между годами в условиях засухи была высокой, а в условиях орошения - низкой. Как видно из рис. 2, в условиях засухи по значению этого параметра сорта были разделены 
на две группы. В первую вошли Безостая 1 , Гобустан, Восторг, Гызыл Бугда, Тале 38, Шеки 1, Аран и Фатима со значениями САТ 460-480 ${ }^{\circ}$, а во вторую - Сонмез 01, Гырмызы гюл 1, Зирва 85 и Муров 2, у которых значения САТ более $500^{\circ}$. Здесь низкий период ФАФЛ у сортов Безостая 1, Восторг, Тале 38 , Шеки 1, Аран и Фатима можно объяснить их поздним колошением.

На рис. 3 сравниваются кривые определения по САТ раннеколосящихся сортов Муров 2 и Зирва 85 с высокой САТ в условиях засухи и позднеколосящихся Тале 38 и Безостая 1 с низкой САТ в условиях засухи. Несмотря на раннее колошение сортов Гобустан и Гызыл бугда, низкое значение их
САТ можно объяснить быстрым высыханием флаговых листьев из-за их физиологической нестабильности.

Как отмечалось выше, взаимосвязь между ранним колошением и значениями степени дневного роста (GDD - СДР) может быть оценена как показатель адаптации к условиям засухи, особенно к поздним периодическим засухам. Наиболее типичным примером разницы между вариантами засухи и орошения является сорт Тале 38 , который выведен для орошаемых земель и имеет плохую засухоустойчивость. Кривые снижения содержания хлорофилла в вариантах засухи и орошения для этого сорта за два года исследований показаны на рис. 4.

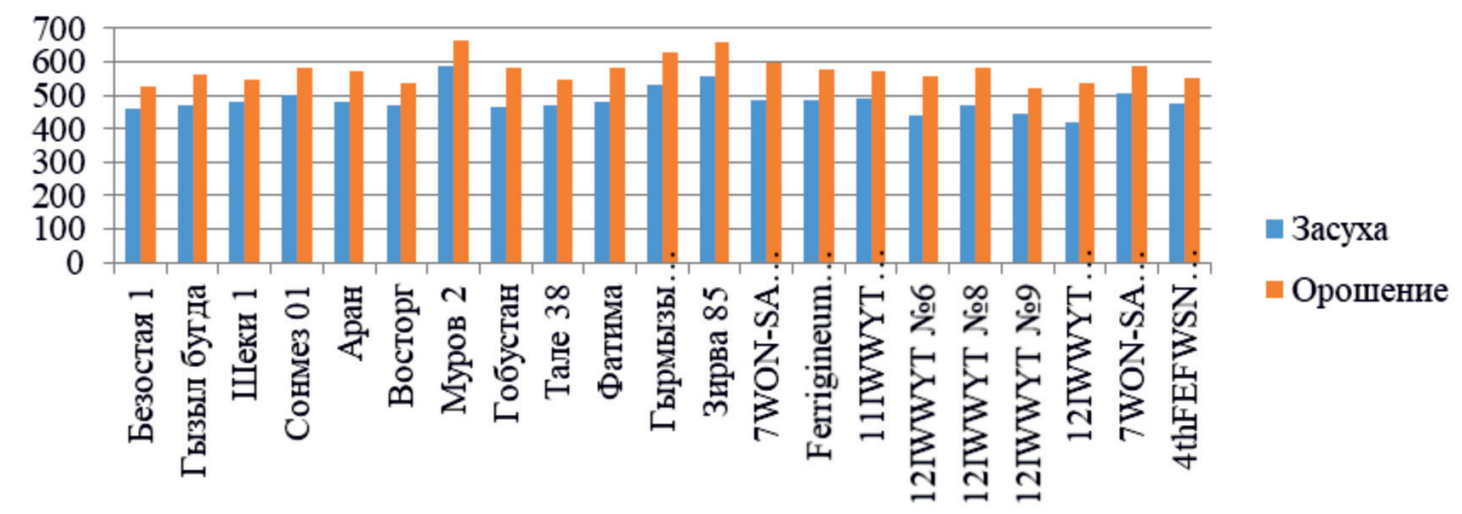

Рис. 2. Период фотосинтетической активности флагового листа в условиях засухи и орошения (в среднем за 2013 и 2014 гг.)
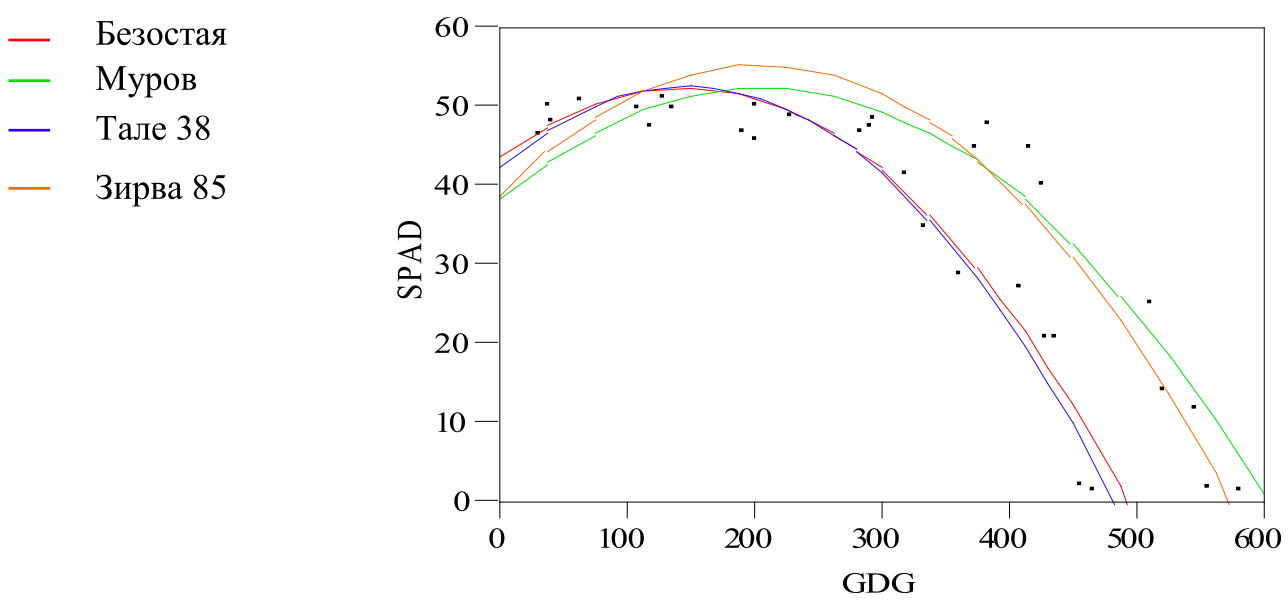

Рис. 3. Снижение содержания хлорофилла во флаговых листьях некоторых сортов в условиях засухи (2013 г.) 


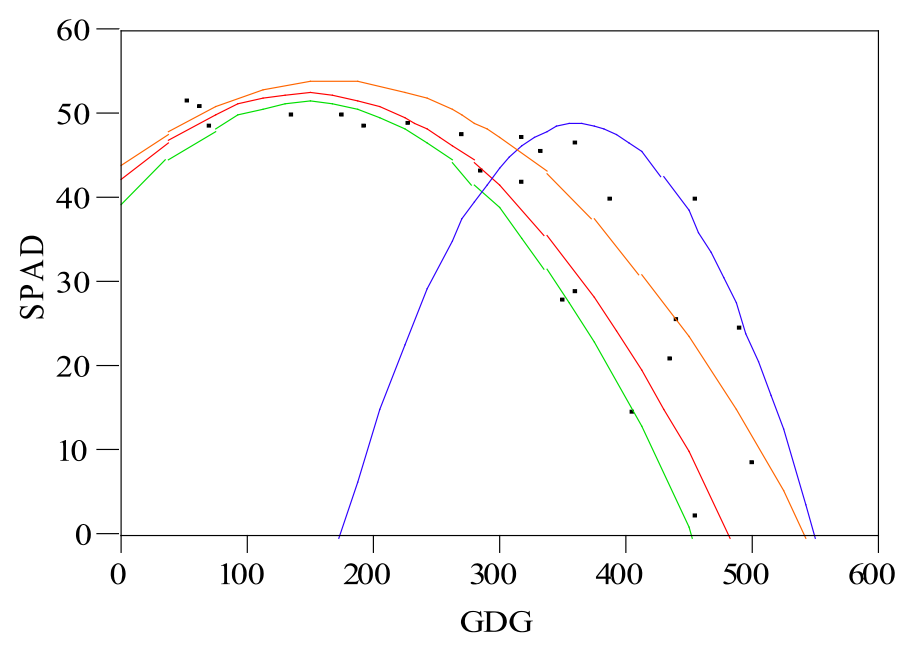

— Тале 38, засуха 2013

— Тале 38, засуха 2014

— Тале 38, орошение 2013

- Тале 38, орошение 2014

Рис. 4. Снижение содержания хлорофилла во флаговых листьях сорта Тале 38 в вариантах засухи и орошения за 2013 и 2014 г2.

Как видно из рис. 4, снижение GDD (СДР) в варианте засухи не было связано только с поздним колошением. У сорта Тале 38 динамика снижения содержания хлорофилла во флаговом листе быстрее, чем у позднеколосяшихся Гырмызы гюл 1, Аран и Шеки 1. Таким образом, можно сказать, что низкая GDD (СДР) у сорта Тале 38 в условиях засухи связана не только с его поздним колошением, но и со слабой засухоустойчивостью.

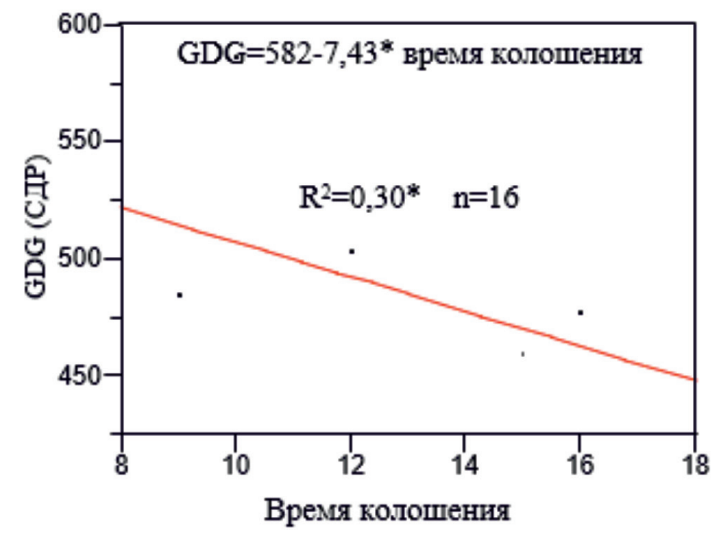

Рис. 5. Корреляиция между временем колошения в варианте засуха и САТ (время колошения принималось как количество дней с 1 мая) (в среднем за два года)

В литературе встречается информация о существовании прямой корреляции между периодом ФАФЛ пшеницы и временем колошения в условиях засухи [11]. Суще- ственная корреляция между колошением и фотосинтетической активностью флагового листа в наших опытах не наблюдалась. Как мы уже упоминали, принимая во внимание, что некоторые генотипы с физиологически слабой засухоустойчивостью (Гызыл бугда, Гобустан, 12 $2^{\text {th }} \mathrm{WWWYT} \mathrm{№6,}$ $12^{\text {th }}$ IWWYT№17, $4^{\text {th }}$ FEFWSN№50), несмотря на их раннее колошение, отрицательно влияли на результаты, они были отстранены от исследования. После этого в варианте засуха наблюдалась обратная корреляция между периодом ФАФЛ и временем колошения, равная $\mathrm{r}=-0,547$ *. Между датами наблюдалась корреляция, равная $\mathrm{r}=-0,547 *$ (рис. 5).

При наступлении засухи в послевсходовый период есть реальная основа для высокого GDD (СДР) и продуктивности у генотипов раннего колошения, чем у генотипов позднего колошения. Однако в этом случае также необходимо продолжение фотосинтетической активности флагового листа генотипа в течение более длительного периода времени. Примерами могут послужить генотипы Гызыл бугда, Гобустан, $12^{\text {th }} I W W Y T$ №6, 12 $2^{\text {th }}$ IWWYT№17, $4^{\text {th }}$ FEFWSN №50. Heсмотря на их раннее колошение, быстрое высыхание флаговых листьев привело к низкому периоду ФАФЛ у этих генотипов. Особого упоминания заслуживает сорт Гобустан. Несмотря на низкий период ФАФЛ, по нашему мнению, на его высокую урожайность повлияло не только раннее колошение, но и другие морфофизиологические параметры. В богарных районах, где про- 
дуктивность зависит от количества осадков, при влиянии стресса засухи на растения на более ранних этапах, раннее колошение теряет свое значение, а параметры физиологической устойчивости генотипа становятся более важными.

В связи с этим имеются литературные данные, где отмечается, что сорта раннего колошения, которые сохраняют ФАФЛ в течение более длительного периода времени, с точки зрения урожайности более эффективны [12]. Также можно сделать вывод, что из генотипов, колосящихся в один и тот же срок, генотипы, физиологически более устойчивые к засухе и с ФАФЛ более длительного периода времени, будут более высокоурожайными в условиях засухи.

\section{Заключение}

Было установлено, что САТ у генотипов озимой пшеницы в условиях орошения выше в условиях засухи, что также зависит от генотипических характеристик растения. В дополнение к тому факту, что CAT связана с временем колошения, физиологическая устойчивость генотипа также играет роль. Таким образом, несмотря на раннее колошение некоторых генотипов, их слабая физиологическая устойчивость привела к низким значениям САТ. У некоторых генотипов позднего колошения САТ была высокой. Учитывая длительность периода фотосинтетической активности флагового листа, сорта Муров 2, Гобустан, Гырмызы гюл 1, Зирва 85 и линия $7^{\text {th }}$ WON-SA №465 обладают наибольшей засухоустойчивостью, и использование этих генотипов в селекционной работе для условий богары считается целесообразным.

\section{Список литературы / References}

1. Aliev J.A. Physiological bases of wheat breeding tolerant to water stress: Proceedings of the $6^{\text {th }}$ International Wheat Conference: Wheat in a global environment. Hungary: Budapest. 2000. Vol. 9. P. 693-698.
2. Long S.P., Marshall C.A., Zhu X.G. Meeting the global food demand of the future by engineering crop photosynthesis and yield potentia. Cell. 2015. Vol. 161. P. 56-66.

3. Allahverdiyev T.I. Impact of soil water deficit on some physiological parameters of durum and bread wheat genotypes. Agriculture \& Forestry. 2016. Vol. 62 (1). P. 131-144.

4. Лисицын Е.М., Амунова О.С. Генетическое разнообразие сортов яровой мягкой пшеницы по алюмоустойчивости // Вавиловский журнал генетики и селекции. 2014. Т. 18. № 3. С. 497-505.

Lisitsyn E.M., Amunova O.S. Genetic diversity of spring bread wheat varieties in terms of aluminum resistance // Vavilovskiy zhurnal genetiki i selektsii. 2014. Vol. 18. No 3. P. 497-505 (in Russian)

5. Reynolds M., Langridge P. Physiological breeding. Current Opinion in Plant Biology. 2016. Vol. 31. P. 162-171.

6. Ram H., Gupta N., Saini J.S. Growing degree day requirements and yield ability of irrigated durum wheat as influenced by sowing time. Agric. Res. J. 2016. Vol. 53. P. 303-306.

7. Aliev J.A. Diversity of photosynthetic activity of wheat genotypes and breeding of high-yield varieties tolerant to water stress: Proceedings of the $12^{\text {th }}$ International Congress on Photosynthesis. Australia: Brisbane, 2001. P. 28-006.

8. Голева Г.Г. Морфо-биологические и селекционные аспекты формирования продуктивности озимой пшеницы (Triticum aestivum L.) в Центральном Черноземье: дис. ... докт. сельскохоз. наук. Воронеж, 2017. 328 с.

Goleva G.G. Morpho-biological and breeding aspects of the productivity formation of winter wheat (Triticum aestivum L.) in the Central Chernozem Region: dis. ... dokt. sel'skokhoz. nauk. Voronezh, 2017. 328 p. (in Russian)

9. Kumari M., Pudake R.N., Singh V.P., Joshi A.K. Association of stay green trait with canopy temperature depression and yield traits under terminal heat stress in wheat (Triticum aestivum L.). Euphytica. 2013. Vol. 190. P. 87-97.

10. Allahverdiyev T.I. Physiological Traits of Durum Wheat (Triticum durum Desf.) and Bread Wheat (Triticum aestivum L.) Genotypes under Drought Stress. Agricultural Sciences. 2015. Vol. 6. P. 848-859.

11. Albayrak O., Bayhan M., Ozkan R., Akinci C., Yildirim M. Effect of drought on morphological and physiological development of bread wheat (Triticum aestivum L.) genotypes at pre and post heading period. Applied Ecology and Environmental Research 2021, ALÖKIKft., Budapest, Hungary. 2021. Vol. 19(6). P. 4251-4263. DOI: 10.15666/aeer/1906 42514263.

12. Киризий Д.А. Фотосинтез и донорно-акцепторные отношения между органами как составляющие продукционного процесса пшеницы // Физиол. Раст. и Генетика. 2015. T. 47. № 5. C. 393-419.

Kiriziy D.A. Photosynthesis and donor-acceptor relationships between organs as components of the wheat production process // Fiziol. Rast. i Genetika. 2015. Vol. 47. No. 5. P. 393419 (in Russian). 